\title{
Memory Change: An Intimate Measure of Persuasion
}

\section{KATHRYN A. BRAUN-LATOUR \\ William F. Harrah \\ College of Hotel \\ Administration \\ Kathryn.latour@unlv.edu}

\section{GERALD ZALTMAN}

Olson Zaltman

Associates

gzaltman@hbs.edu

A major goal for advertising is to have an enduring emotional impact on an audience by facilitating their creation of personally relevant understandings of an advertisement. This is achieved through a process of cocreation in which consumers integrate advertising content with their own attitudes, beliefs, and values to produce the meaning of an advertisement. This article proposes an approach to evaluating advertisements that builds on the reconstructive nature of memory, the dominant view of memory today. The reconstructive view of memory holds that the memory for the same event is different each time it is recalled and that the person doing the recalling is unaware of these changes. We present an experimental paradigm that assesses advertising's influence on consumers' own memory of their beliefs. We demonstrate that advertising can unconsciously alter consumers' beliefs as reflected by a change in how consumers recall their earlier reporting of these beliefs following an advertising exposure. That is, advertising that causes consumers to remember differently earlier (preadvertising exposure) reported beliefs and in which the change is in the direction of the advertisement's message is an advertisement that contains information the consumer has unconsciously adopted as their own and therefore is likely to be personally relevant and to have an enduring impact on their emotions.

"Asked about the power of advertising in research surveys, most agree it works, but not on them" (Clark, 1985, p. 13). Luckily for advertisers, this belief about the impact of advertising on personal beliefs does not appear to represent reality. Most psychologists agree that consumers have little direct access to their own thought processes (Gardner, 2004; Libet, 2004; Nisbett and Wilson, 1977; Pinker, 2002; Wegner, 2002; Zaltman, 2003), and neuroscientist Joseph LeDoux (1996, p. 32) warns against the use of such selfreport surveys: "We have to be very careful when we use verbal reports based on introspective analyses of one's own mind as scientific data."

Consumers and marketers generally distinguish between two types of information used to make de- cisions: internal and external. Internal information is that which the consumer has gained through experience; external information is information they may have encountered that attempts to influence their beliefs. When making their decisions, consumers prefer to believe they are relying on their own internally generated information because "people rarely derogate themselves as sources of information" (Smith and Swinyard, 1983, p. 257).

Traditionally, advertising has been viewed as an external source whose goals encompass informing, persuading, or reminding consumers about the advertised offering. The dependent measures researchers have used to assess advertising's impact have followed these three general goals, such as measuring advertising awareness, attitude 
toward the advertisement, or brand attitude. However, regardless of an advertisement's intent, ultimately the advertiser hopes to influence consumers as a result of the exposure. Ideally, the advertising content moves from being considered an external source and has become integrated into the consumers' own internal knowledge system. This is the primary way in which advertising can have an enduring emotional impact on consumers.

Many researchers have sought ways to measure an advertisement's integration into consumers' internal belief systems. For example, consumers may be asked to rate their involvement in the advertisement, their emotional reaction to the advertisement, or the personal relevance of the advertisement. Such measures rely on questions about the advertising itself but often fail to reveal the true impact of the advertisement on consumer cognition. These measures may be biased by other information such as brand "liking," which may result in a "halo effect" that distorts how a person responds to the copy test questions. More broadly, such measures depend on the consumer's ability to selfreport; and as mentioned in the initial paragraph, consumers may not be able to do that accurately. This may be in part due to cultural factors, where consumers tend to discount the influence of advertising (Smith and Swinyard, 1983), and in part due to cognitive factors, in that they might not have the ability to accurately access that information (Libet, 2004; Wegner, 2002; Zaltman, 2003).

We suggest that the ultimate persuasion occurs when advertising becomes internalized into-blends with-the consumers' belief structure that in turn fosters enduring emotional impact (Fauconnier and Turner, 2002; Kovecses, 2000). For instance, after seeing an advertisement, we believe that consumers may unconsciously adopt the claims made in the advertisement as

We suggest that the ultimate persuasion occurs when advertising becomes internalized into-blends with-the consumers' belief structure that in turn fosters enduring

\section{emotional impact.}

their own. This internalization or unconscious adoption of the information is made possible through a reconstructive memory process. By asking consumers to describe their beliefs in advance of an advertising exposure and then asking them to recall their prior-stated attitudes or beliefs following an advertising exposure, one can assess the direction and degree of the advertisement's influence by assessing the changes that may have occurred. The absence of change in reported attitudes would indicate no internalization or ownership of the message and suggests that the advertisement had no effect. However, if consumers "remember" their earlier thoughts and feelings as being more/less positive following an advertising exposure, the change can be attributed to the impact of the advertisement. In this case, consumers have unconsciously "forgotten" their prior attitudes/beliefs and adopted new ones stimulated by the advertising (if indeed the advertising was persuasive). The new memory or "story" is the product of previous beliefs interacting with those contained in the advertisement. This may also involve instant "source forgetting" where consumers mistakenly attribute the learned advertising information to having been their own personal consistent beliefs/ attitudes all along. Consumers consider themselves as the storyteller, not the external communication.

The ownership of these new beliefs or attitudes is important because such overall evaluations are more resistant to change over time (Feldman and Lynch, 1988). Because advertising is often discounted by consumers (Clark, 1985), advertisements that work by integrating themselves into the consumers' own belief structures may be more influential in the long run. This is important from a research standpoint because this internalization happens below consumers' conscious awareness and is unlikely to surface through traditional verbal self-report measures.

This article begins with a brief review contrasting the reconstructive view of memory with the more widely used reproductive view of memory. Evidence is introduced in support of a reconstructive view of memory and how this theory can provide insight into the internalization advertising information. Our study tests an animatic-stage advertisement for a new drug against a well-known competitor. In addition, we look at whether or not advertising-rating or advertising involvement scales are related to the degree of memory change and then examine advertising's influence on memory using more implicit measures of effect. The results indicate a memory integration paradigm might be especially beneficial in uncovering advertising effects that consumers cannot readily acknowledge.

\section{BACKGROUND}

\section{Reproduction versus reconstruction}

Recent thinking in advertising (Hall, 2002) and marketing (Braun, 1999; Zaltman, 2003) has addressed the dynamics of the 


\section{Because advertising is often discounted by consumers,}

\section{advertisements that work by integrating themselves into}

\section{the consumers' own belief structures may be more influ-}

\section{ential in the long run.}

human memory system and, in particular, the reconstructive view of recall. This view has long been recognized by psychologists, with Sir Frederick Bartlett (1932) being one of the first 20th century researchers to assign a reconstructive view to memory. Bartlett viewed memory as a tool by which we give meaning to our world. He believed that in order to make a sensible picture of the world, it may be only natural that the memory system mixes facts and our attitudes in such a way that they become indistinguishable. The reconstructive view finds that every act of remembering involves a reconstruction of information, and this process at times leads to inaccuracies (Belli, Lindsay, Gales, and McCarthy, 1994). "Thus, each memory event is dynamic and context-sensitive-it yields a repetition of a mental or physical event that is similar but not identical to previous acts. It is recategorical: it does not represent an original experience exactly" (Edelman, 2004, p. 52; see also Schacter, 2001).

In contrast, the traditional reproductive theories of memory imply that stored mental representations of past experiences are elicited intact during recall (Reber, 1985). This view is implicit in how advertisers model the effects of advertising, believing that a one-to-one correspondence exists between what was seen and what can be later retrieved. This reasoning underlies the use of recall and recognition measures of advertising exposure. The general belief is that memory for a past experience, such as viewing an advertisement, is permanent (Bettman, 1979), and under the right conditions experiences can be turned on and reviewed much like a videotape. In a recent Journal of Advertising Research article, Ehrenberg and colleagues advocated such a view: "Once a message or image is placed into long-term memory, it seems virtually never to be forgotten (e.g., Hunter, 1964; Franzen and Bouwman, 2001). Formal recognition tests and general experience have long confirmed this (e.g., recognizing a picture seen once twenty years ago, or the first chord of Beethoven's Seventh, for those who know the Seventh). The capacity of memory is without question vast-each of us routinely remembers so much" (Ehrenberg, Barnard, Kennedy, and Bloom, 2002, p. 10).

This traditional view of a veridical correspondence between our experiences and bits of information in memory is intuitively appealing. Activating a memory would just mean "turning on" one of these objectively accurate bits, much like clicking the mouse on a computer and retrieving a stored document. However, consider the case of Nixon legal counsel John Dean's Watergate testimony below that differentiates one's belief in a reproductive memory system from what actually occurs through our reconstructive memory system.

To prepare for his testimony, Dean requested access to external information sources, such as newspaper reports for the dates in question. He did not refer to his own notes. Thus, he recreated the memories of his conversations with Nixon and others based on those external reports. Yet in his testimony he was quite convincing of his belief in the veridicality of these "internally generated" memories. In fact, some referred to him as a "human tape recorder" (Neisser, 1981).

Dean did not know at the time he gave his testimony that there were in fact actual taped backups of his conversations with Nixon. Had Dean's memory followed a reproductive view of memory, then Dean's testimony would have corresponded well with those taped backups. However, Dean's recollections were much more consistent with what memory reconstructive theorists have proposed. Dean demonstrated egocentric tendencies where he remembered being complimented by Nixon for "good work," when no such flattery was given. Hindsight bias infiltrated his recollections when he remembered warning Nixon of pursuing options that were later dismal failures (while the taped report offered evidence that the opposite might be true). Dean lost his context of time, and when pieces of conversations had occurred. Discrete time periods, sometimes even months apart, became blended together as a singular representation.

Generally, we are not "tested" for accuracy of a prior state as was John Dean, so we are typically unaware of how our memories have changed. Memory distortion has been shown in a number of different contexts-from eyewitnesses remembering people or things that were not at the scene (Loftus and Pickrell, 1995), to how one heard about and what one had expected the outcome of the O.J. Simpson trial to be (Schmolck, Buffalo, and Squire, 2000), to misremembering seeing the crash of the first plane into the World Trade Center on 9/11 on TV (Pezdek, 2003). In an advertising setting, such changes in 
memory would indicate the internalization of the advertising information. In the next section, we review attitude change research pointing toward memory reconstruction as the mechanism underlying persuasion.

\section{Internalization of persuasive information through memory reconstruction}

Research in social psychology suggests that memory reconstruction may mediate attitude change. For instance, in an early study, Goethals and Reckman (1973) surveyed people that were biased pro or con toward racial integration of schools through busing and assessed their attitudes at that time. Seven days later, they were exposed to counter-attitudinal arguments delivered by a convincing spokesperson. Attitudes were checked again. In addition, they asked participants to recall their pretest attitudes. As cognitive dissonance theory would predict, the newer attitudes moved in the direction of the counter-attitudinal messages. However, an unexpected result occurred in the recall test in which participants' recalled their previous attitudes differently and in the direction of the counterattitudinal messages. Goethals reported that several participants wanted to see their pretest attitude measures and were "genuinely surprised to find the change." What appears to have happened is that the participants were unable to remember their prior attitudes because they had become unconsciously altered by exposure to the counter-attitudinal information.

\section{Application to advertising}

There is a belief among advertising researchers that persuasion through advertising takes a long time, so the aforementioned study may not be applicable to the advertising testing domain. This belief is supported in a classic study by Maloney (2000, p. 6):
"It may be true that if one is dealing with a small enough 'bit' of stimulusresponse unit, learning occurs in a single trial. An attitude, however, is not the smallest irreducible element. Therefore, when we are talking about attitude change, we are talking about a process that presumably does not occur in a single instant of time. This is true even though the manifestation of a change in attitude may occur as a single event when sufficient covert 'bits' have been learned to result in a kind of 'flapover' in response to a question."

Indeed, in previous studies on attitude change, there was a week or more delay before the memory change was observed. Research in cognitive psychology, however, finds that such a delay is not necessary for adoption of information in memory (Belli, Lindsay, Gales, and McCarthy, 1994). And although it is true that attitudes may not be reducible to a single element, the information on which attitudes are formed is stored as neurons in the brain, the smallest elements of cognition, and those neural networks are in continuous change (Edelman, 2004; Zaltman, 2003). Bartlett (1932) expressed the belief, and now neuroscience is confirming it, that memory and attitude are an interrelated process (Crick and Koch, 1998; Edelman, 2004; Schacter, 1996, 2001; Squire and Knowlton, 1999).

Braun and Zaltman (1998) were interested in whether time was indeed necessary for attitude and memory change to occur. In their study, they had consumers view a movie clip and then rate how they thought it would do in the actual market. Twenty minutes later, participants were given either a positive or negative critical opinion of the movie, in which they were asked to assess how well it was written. Five minutes later, participants were asked to recall how they had earlier rated the movie. These participants were told that they were taking a memory test and to do their best to recall what they had earlier predicted. If they had forgotten, they could indicate that on the questionnaire. The researchers found a memory shift in those recalled items; the consumers that had read the positive critical opinion believed they had rated the movie more favorably than they actually had, and vice versa for the negative criticism group. None of the participants said they "forgot" their earlier rating.

\section{Consciousness of the memory process}

No two memories involving the same event are ever exactly the same, as the patterns of activation involved in retrieving information will differ each time the event is recalled (Edelman, 2004). These differences may often be very small and of no practical consequence. In other instances they may also be substantial and have great consequence as in certain cases of false memory (Loftus and Ketchum, 1996). Whether it is as simple as recalling one's own telephone number or as complex as remembering an emotional childhood experience, this reconstructive process persists and is the accepted view of memory in psychology today. The ease with which some memories seem to "pop" into our minds reflects our unawareness of this complex reconfiguration (Crick and Koch, 1998; Wegner, 2002).

External information can distort memories without consumers' awareness, thereby giving them the false sense of security that it is their own experiences which drive their decision making. "New information invades us like a Trojan horse, precisely because we do not detect its influence" (Loftus and Pickrell, 1995, p. 720). Research on hindsight bias finds that projection of new knowledge into the past is accompanied by a denial that such outcome information has influenced 
one's judgment (Hawkins and Hastie, 1990). This is consonant with what Goethals and Reckman (1973), Ross (1989), Braun (1999), and Zaltman (2003) all found in their memory/attitude change experiments: participants were unaware that their memories had been altered. Neuroscientific evidence confirms that the brain activity when recalling a "true" memory is very similar to that involved when recalling a "false" memory-both show activation in the hippocampal region that is associated with emotion. There is a conviction when recalling a memory that it "feels" real, regardless of its actual veracity (Schacter, 1996; Squire and Knowlton, 1999).

\section{Pre/posttesting designs}

In this study, consumers were asked at one point in time about their beliefs on an issue, then later exposed to an advertising message intended to influence those beliefs. Subsequently they were asked to repeat the information provided initially (in a memory test) and, a few days later still, were again asked to recall their prior stated beliefs. The use of pre/posttesting designs of attitude change is quite common to most advertising research (such as the ARS Persuasion Measure, Blair and Rabuck, 1998). Such designs are important because they take into account idiosyncratic preexisting differences among advertising conditions that may bias how an advertising campaign is received (Haley and Baldinger, 2000). These differences in knowledge, or of competitor activities, may be particularly relevant when launching a new brand into an already established product category (Burke and Srull, 1988). However, it is important to distinguish how advertisers have typically used the pre/postdesigns from the design proposed in the current study.

Many advertising researchers believe that attitude/belief changes cannot be

Neuroscientific evidence confirms that the brain activity when recalling a "true" memory is very similar to when recalling a "false" memory-both show activation in the hippocampal region that is associated with emotion.

monitored after one viewing session, and the pre/postdesigns are often administered over a longer period of time in which consumers have been potentially exposed to the advertising campaign numerous times. The problem is that in allowing greater time between initial and postattitude measures, more potentially intervening material can also be presented that can interfere with attitudes. Also, there is no way to know whether or not consumers have actually been exposed to the advertising campaign (and if so, for how many exposures). Therefore, there is a lot less control over the situation in the typical pre/postdesign compared to a more controlled experimental setting.

Perhaps more problematic is the manner in which questions are asked of participants in the attitude (or choice) studies. Because participants are aware that the researcher is interested in assessing their attitude changes (or choices) based on the advertising exposure, some may overestimate the impact of advertising by indicating more favorable attitudes; others may do the reverse and underestimate, because they do not want to believe that the advertising had an impact on their beliefs. Both types of effects, due to experimenter demand or social desirability, create problems in the interpretation of these explicit attitude measures. This criticism applies fully to those situations in which consumers are given a TV program to watch with various advertisements em- bedded and then later asked about the target advertisement.

In contrast, the memory integration paradigm introduced here asks participants to recall their prior attitudes/beliefs as accurately as possible. There is no indication that the researcher in any way wants them to include their assessment of the advertising. In fact, the contrary is true: they are explicitly directed to be as accurate as possible because they are involved in a memory test. These instructions limit the self-preservation bias and demand effects. Therefore, whatever changes occur in their recall measures can be reliably attributed to how much they internalized the advertising as being their own original thought, versus how much they might be consciously weighing the advertising as they make their current attitude judgments. The highly controlled viewing setting allows us to isolate the impact of the advertising's message on beliefs.

\section{ADVERTISING STUDY}

The purpose of this study was to determine whether a memory integration paradigm would be useful in an advertising research setting. It is important to note that the advertising environment is very different from the attitude change situations studied by social psychologists cited earlier. First, information used in the social psychology experiments could be considered more credible than advertising and thus more likely to be accepted as one's own belief (Schacter, 1996). However, 
because memory changes occur at a preconscious level, it may be that the memory integration paradigm can also capture the extent to which advertising information is integrated into consumers' belief systems. This study incorporates memory change measures and more familiar self-report measures of advertising influence. Additionally, we incorporate an implicit memory task (word completion) to determine if the advertising exposure and subsequent memory changes would be related to other indirect measures of influence. It is important to determine if observed results in a lab situation last over time (e.g., McQuarrie, 1998), so we also test for the persistence of memory change subsequent to the laboratory session. Any persistence of change would suggest that the message had become well integrated into consumers' knowledge structure in an enduring way.

The advertisement-testing environment also sets some constraints for certain brands, particularly new brands. Prior exposure to competitor advertising is likely to influence how that new brand/advertisement is perceived. Additionally, the familiarity associated with the current leader may unfairly bias the ratings toward that brand's advertisement and not give the new entrant's advertisement a "fair shake." This is particularly problematic when using absolute measures such as recall or attitude toward the advertisement. A relative measure that could isolate prior knowledge from the influence of the test advertisement would be beneficial for testing; the memory change measure is designed to parse out such prior influence.

Another difference in the advertisementtesting situation has to do with the advertising itself, mainly the cost. The social psychology experiments mentioned earlier involved simple print or verbal information. In advertising development, as one moves from the simple storyboard to the animatic advertisement to the finished product, costs accelerate. Ideally, one would want to find a method that could be diagnostic and fix the advertisement before much money had been spent.

To determine whether this paradigm might be effective for new brands with a relatively unfinished advertising product, we chose to test an animatic advertisement for a new prescription medication (brand A) against a finished advertisement being run by an existing market leader (brand $B$ ) and a control group where no advertisement was seen. While animatics cannot be expected to have the same impact as a finished TV advertisement, evaluative research on animatics is essential input for improving the final advertisement and hence an appropriate form of communication to test. To the extent that the animatic version produced results directionally consistent with the finished advertisement, we can have at least some confidence in the use of this approach as a developmental tool in the early stages of testing alternative advertisements.

Before running our main study, we conducted a pilot test on 14 consumers who were part of the target market for the tested drug (each was paid $\$ 50$ for his/ her time) to determine if the unfinished nature of the commercial would detract from their acceptance of the advertisement. Each participant was asked for his/ her attitude on several measures regarding the treatment of the participants' health conditions a few days prior to the advertisement viewing session. At the session, they were told before viewing the advertisement that this commercial was in unfinished "animatic" form. They were shown the advertisement three times and asked to give written feedback and rate it on a number of scales. They were also given a short distraction task (word completion, which is used as an implicit measure in the main test), and then asked to recall their prior stated attitudes and to indicate "don't remember" if they could not recall what they had previously said. All participants showed a memory change on at least one of the attitude measures. No one seemed to have a problem with viewing the advertisement in a less than finished form.

\section{Method}

Participants. One hundred thirty-three participants (69 females, 64 males) having an average age of 53 and coming from north suburban Chicago participated in our study. They were recruited by a market research firm, and to be eligible they needed to be between the ages of 40 and 70 and diagnosed with the health problem addressed by the test drug advertisements. Participants had to be available for a pretelephone interview 48 hours prior to the advertisement testing session, available to watch the advertisement in a testing session, and available for a follow-up call two to three days after the session. They were each paid $\$ 50$ for their participation in the study.

Participants were assigned to appear at one of the advertisement-testing sessions (brand A, brand B, or control, where no advertisement was seen). These three groups were recruited to be split on gender and usage of medication to treat their health problem. All groups were overrecruited: 41 showed for the brand $\mathrm{A}$ group, 48 for brand B, and 44 for the control group. For the follow-up call, one person from the brand A group and four people from the control group could not be contacted.

Procedure. Participants were recruited based on the above specifications, and at that time the recruiter made an appointment to speak with them two days before the testing session. For the initial attitude measures, they were asked to state their 
agreement/disagreement with the target belief statements on a 10-point scale, where greater agreement was associated with higher numbers. The first four statements concerned their overall beliefs about needing to take prescription medication for their condition, how much they believed that their situation could be remedied through lifestyle changes alone, how safe they perceived the prescription medications to be, and their level of satisfaction with their current treatment of their condition. These more general statements were delivered in random order among the participants.

The next six statements concerned their attitudes/beliefs toward brands A and B. For each brand, they gave their beliefs about that brand's effectiveness, its ability to solve their problems and help them to live their lives better, and their likelihood of purchasing that brand in the future. Participants were given a 10 -point scale on which to rate each brand, with higher numbers indicating more positive beliefs/ attitudes or intent. After getting the participants' responses, the recruiter reminded them of their time for the upcoming session, and provided driving directions to the market research facility.

On the day of testing, participants arrived at the market research facility and were led into a large room where chairs were in rows in front of a large screen. Participants were given a questionnaire, told to take a seat and to get comfortable. They were instructed not to talk to one another, told that we were interested in their personal beliefs, and informed that this was not a "focus group." Those in the advertisement viewing conditions were told they would be watching a commercial and providing both detailed written and rating information on the advertisement.

The advertisements were shown three times: for the first time, participants were just asked to indicate the brand name; the second time, they provided more extensive written feedback; and following the third viewing, they rated the advertisement on a number of items such as their attitudes toward the advertisement.

Following the advertisement viewing and rating session, the participants had five minutes to perform a word completion task designed to create some disassociation/ distraction between the advertisement and later measures as well as to determine if the advertising exposure "primed" certain words or feelings. Those in the control group skipped the advertisement viewing and rating, and were given the word completion task immediately.

After five minutes, the groups proceeded to the memory measures, where they saw the same 10 items about treating their conditions that they had been asked about two days earlier. They were told this was a memory test, and also the following: "To the best of your ability, answer the questions below as you did earlier. If you cannot recall exactly what your answers were, indicate what you probably would have said." The moderator explained that sometimes hearing the questions may help the participants remember, and she read aloud each of the 10 statements as participants recalled their prior beliefs (as per Tulving's encoding specificity hypothesis, Thomson and Tulving, 1970). Following those measures, participants were asked to indicate their confidence in their memories and whether or not they felt the advertising influenced their memories (for advertisement viewing conditions only).

Afterward, participants proceeded through the questionnaire at their own pace. If they were in one of the advertising conditions, they rated the advertisement on a standard advertising involvement scale. All of them then proceeded to some general questions about their behavior. The session lasted approximately 40 minutes for the advertising conditions and about 30 minutes for the control condition. After the participants completed their questionnaires, they turned them in to the moderator and went to another room to claim their participant's fee.

Two to three days after the session, they were contacted again by phone. So as not to reveal the true nature of the contact, they were first asked how much they enjoyed the session and what they had done afterward. Then they were told we were interested in their current beliefs/ attitudes toward treating their health problem and that they would be asked the same questions as earlier. The same 10 attitude/belief questions were asked (with the first four randomized), and they were thanked again for their time.

\section{Measures}

Two days prior to the session participants were asked about their attitudes/beliefs about treating their health problems and asked the same questions again at the session following a standard distraction task immediately after viewing the advertisement (or no advertisement in the case of the control group). It was expected that if the message contents were effectively internalized by participants they would display memory changes in the direction of the advertising information. That is, there would be a new set of meanings created by participants that would be a blend of their earlier beliefs and those contained in the communication. In the following tables and charts, these memory changes are defined as the difference between the initial and recalled attitudes, "Memory $\Delta 1 . "$ Once again, participants were told this exercise was a memory test and asked to provide as best they could the same answers provided two or three days earlier when initially contacted by phone. No explicit reference was made to the advertisement. 
Participants were also contacted two to three days following the advertising exposure session and again asked about their attitudes. For this questioning, there was no reference made to their prior results; rather, they were asked to report their current attitudes/beliefs. Our interest in conducting this follow-up contact was to determine whether an observed memory change during the advertising exposure session was merely a context effect that would disappear over time, or if the information had become internalized into their belief systems to continue to influence their attitudes. In the following tables and figure, we look at the difference between the first and last attitude measures, which we call "Memory $\Delta 2$. ."

We found that these two change measures were highly correlated, $r=.64$, suggesting that there was no decay of the advertising information on memory. In fact, in some instances we found an even greater influence of the advertising on memory change over time, suggesting a "sleeper effect" of the advertising information. This effect is consistent with many views of memory: over time, the source information (advertisement) decays, but the content of the information is retained (Schacter, 1996). Because consumers no longer attribute the advertising information to its correct source, they weigh the information as being more credible (as coming from their internal knowledge base). In our reporting of the results below, we refer mainly to the Memory $\Delta 1$ results, as the Memory $\Delta 2$ results followed the same pattern (if not more strongly).

\section{Memory change results}

Memory change can be assessed in several ways. One is to consider the number of items exhibiting change for each individual that was in the direction of the advertising message. For instance, the $a b$ - sence of change on any measure would indicate no influence of the advertising, and changes on several measures would indicate that the advertising had some effect. We found that those in the brand $\mathrm{A}$ advertising condition (the animatic for the new brand) changed on more of the memory items $(\Delta 1), X=3.4$, than those in the brand $B$ condition, $X=2.7$, and the control condition, $X=1.7$. Using the general linear model, with condition as the factor, we found the model to be significant at $F_{(2,132)}=13.17, p=.001$, but that only the brand A condition was significantly different than the control.

Following the memory recall items in the main session, participants were asked how confident they were that they were correctly able to recall their prior attitudes (on a scale where $1=$ not at all confident and $10=$ extremely confident). One could argue that those who were the most influenced may be overall less confident and subject to change again in the future. We found, however, no significant difference in confidence across the three groups, $X=7.0$ for brand $A, X=6.5$ for brand $\mathrm{B}$, and $X=6.9$ for controls.

In addition to asking participants about their confidence in recall, we also asked those in the two advertising conditions how much they felt they relied on the advertising when making their memory judgments. Those in the brand A condition were more likely than those in the brand $\mathrm{B}$ condition to suggest that the advertisement had an influence, 36 percent versus 19 percent, significantly different at $\chi_{(N=88)}^{2}=3.4, p=.06$. However, in both advertising conditions more people felt they were relying solely on their past memories than the advertising, 64 percent in brand $A$ and 81 percent in brand $B$, suggesting that for the most part people were discounting the advertising's impact. The uniqueness of the animatic could account for the greater salience of that exposure.
One might conclude that those who were more confident in their recall reported less reliance on the advertising, but there was virtually no correlation $(r=-.03)$ between the two factors. We also looked at the relationship between confidence and memory: were those who were more confident better recallers? Here, too, there was no significant association observed, $r=-.07$. Finally, we looked at the relationship between those who said they relied more on the advertising and the total number of items on which they had changed impressions; these were also uncorrelated, $r=-.05$. The lack of correlation in these instances is important. Participants were not consciously aware of the alteration in their attitudes/beliefs as a consequence of the advertisements. That is the power of memory reconstruction.

One way to assess the impact of the advertising on the recollection process is by looking at the variance in the distributions of the memory items themselves. For instance, if everyone was remembering their prior attitudes correctly, there would be a very tight distribution around the average reported score for each measure (allowing for some reporting error). However, if the distribution around the mean on the measures were wider, more varied, that would suggest the advertising was altering how those prior attitudes were recollected. A more variable distribution would suggest greater consumer confusion; a tighter distribution around the mean would suggest more accuracy. We found that in both advertising conditions the distribution of recalls at advertisement viewing was more varied, 3.7, compared to a variance of 2.2 in the control condition. Over time this continued, where in the measures after the session, variances in the advertising conditions continued to be higher, at 4.1 in brand $B$ and 4.2 in brand $\mathrm{A}$, compared to 3.3 in the control condition. 
In both advertising conditions more people felt they were relying solely on their past memories than the advertising ... suggesting that for the most part people were discounting the advertising's impact.
While this greater variance is evidence for the advertising's impact on recall, it is more important to look for the direction of that impact. Table 1 summarizes the directional predictions of the advertising's impact on consumer recollection of the 10 measures, and the Table 2 provides the actual results. Notice that in some cases it is predicted that people will think they had a more positive initial attitude than they actually did (the $\uparrow$ ), because the advertisement was trying to convey that medication is necessary for many people, making people more accepting of the idea of taking a prescription drug. In other cases, the attitude is predicted to go down. For example, consider the graphed results in Figure 1 where it is predicted that the participants may remember being less supportive of the view that "diet and exercise are enough" after viewing advertisements intended to influence that belief. Time 1 referred to in Figure 1 is the mean of the first measure of that belief (by group), time 2 is the mean group recall average after viewing the commercial, and time 3 is several days after the session.

The final measures were specific to each brand; it is expected that those who see the brand $A$ advertisement should remember being more favorable about that brand's effectiveness, ability to add "balance" to one's life, and their likelihood of trying it in the future; and the same is true for the brand B measures when one sees that commercial. Additionally, it is suspected that the advertisements may have some negative impact on the competition, where those who saw the brand $A$ advertisement, for instance, recall being less positive about brand $\mathrm{B}$.

As shown in Table 2, both brand A and brand B impacted participants' memory of their earlier stated beliefs regard- ing diet and exercise and their views on taking medications for their condition (Questions 1 and 2). The third question addressed safety issues, and the fair balance statement in which the advertisement mentions side effects of the drug appeared to hurt brand $\mathrm{A}$ more in the short term, though over time participants "forgot" those concerns. Question 4 addressed current satisfaction, and brand $A$, the new brand, had more impact on remembered satisfaction than the market leader brand B's advertisement.

The remaining questions pertained to attitudes toward brand $\mathrm{A}$ and brand $\mathrm{B}$ directly. Seeing the brand B advertisement seemed to have little impact on

\section{TABLE 1}

\section{Memory Predictions}

Measure
Prediction

Q1: I will be able to keep my $X$ down by eating $X$ diet and without $\quad$ Brand $A: \downarrow$ taking a prescription medication.

Brand B: $\downarrow$

Q2: I will need a X prescription medication to help lower my $X . \quad$ Brand $A: \uparrow$

Brand B: $\uparrow$

Q3: Prescription medications for $X$ are safe for me to take.

Brand $\mathrm{A}: \uparrow$

Brand B: $\uparrow$

Q4: Satisfaction with your current method of treatment?

Brand A: $\downarrow$

Brand B: $\downarrow$

Q5: How effective do you feel brand B would be for lowering your X? Brand A: $\downarrow$

Brand $B: \uparrow$

Q6: Brand $B$ helps keep $X$ under control and allows me to live life more enjoyably.

Brand $A: \downarrow$

Q7: How likely would you be to try brand $B$ to lower your $X$ ? $\quad$ Brand $A: \downarrow$

Brand B: $\uparrow$

Brand B: $\uparrow$

Q8: How effective do you feel brand $A$ would be for lowering your $X$ ?

Brand $\mathrm{A}: \uparrow$

Brand $B: \downarrow$

Q9: Brand $A$ helps keep $X$ under control and allows me to live life more enjoyably.

Brand A: $\uparrow$

Brand $B: \downarrow$

Q10: How likely would you be to try brand $A$ to lower your $X$ ?

Brand A: $\uparrow$

Brand B: $\downarrow$ 


\section{TABLE 2}

\section{Memory Change Results}

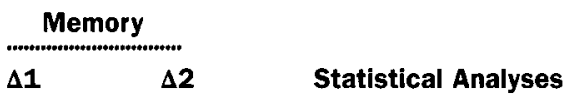

\section{Q1: Bellef about healthy Iffestyle solving problem}

$\begin{array}{lrrr}\text { Brand A } & -.68 & -.68 & \text { Brand A was statistically different than the control at } t(83)=2.23, p=03 \text { for both Memory } \Delta 1 \text { and } \Delta 2 \text {; } \\ \text { Brand B } & -.79 & -.79 & \text { brand B was significantly different than the control at } t(90)=2.0, p=.04 \text { for both Memory } \Delta 1 \text { and } \Delta 2 \text {. } \\ \text { Control } & .02 & .02 & \end{array}$

\section{Q2: Bellef about needing prescriptlon medication to solve problem}

$\begin{array}{lrrl}\text { Brand A } & .24 & .85 & \text { Brand A was statistically different than the control for } \Delta 1 ; t(83)=1.43, p=.1, \text { and } t(78)=2.5, p=.01 \text { for } \\ \text { Brand B } & .50 & .67 & \text { Memory } \Delta 2 \text {; brand B was statistically different than the control at } \Delta 1, t(90)=2.3, p=.02 \text { and for } \Delta 2 \text {, } \\ \text { Control } & -.38 & -.17 & t(86)=1.43, p=.1 \text {. }\end{array}$

\section{Q3: Concern about safety of prescription medication to treat problem}

$\begin{array}{lrrl}\text { Brand A } & -.54 & .22 & \text { At for } \Delta \mathbf{1} \text {, brands A and B were statistically different, } t(87)=1.35, p=.09 \text {, but the effect disappeared over } \\ \text { Brand B } & -.08 & .31 & \text { time. Brand B was significantly different than the control at } \Delta 2, t(86)=1.49, p=.07 \\ \text { Control } & -.52 & -.27 & \end{array}$

Q4: Satisfaction with current method of treating problem

$\begin{array}{lrrl}\text { Brand A } & -.34 & -.32 & \text { Brand A was statistically different than the control, } t(83)=1.27, p=.1 ; t(78)=1.41, p=.08, \text { for Memory } \\ \text { Brand B } & -.23 & -.19 & \Delta 1 \text { and } \Delta 2 \text {, respectively. There was no significant difference for brand B (either time period). } \\ \text { Control } & .11 & .30 & \end{array}$

\section{Q5: Bellef in effectiveness of brand $B$}

$\begin{array}{lrrl}\text { Brand A } & -.09 & -.25 & \text { For Memory } \Delta 2 \text {, brands A and B were statistically different at } t(87)=1.76, p=.08 \text {. } \\ \text { Brand B } & .02 & \mathbf{. 3 7} & \\ \text { Control } & -.09 & -.09\end{array}$

\section{Q6: Bellef that brand $B$ can Improve their IIfe

$\begin{array}{llll}\text { Brand A } & -.43 & -.35 & \text { No statistically significant differences. } \\ \text { Brand B } & -.25 & -.04 & \\ \text { Control } & -.13 & -.27\end{array}$

\section{Q7: Likellhood to buy brand $B$}

Brand B $\quad 0 \quad .24$

Control $\quad-.43 \quad .01$

\section{Q8: Effectiveness of brand $A$}

$\begin{array}{llll}\text { Brand A } & .85 & \mathbf{1 . 1 0} & \text { For Memory } \Delta 1, \text { brand A was significantly different from brand } B, t(87)=2.3, p=.02 \text {; and from the control, } \\ \text { Brand B } & .02 & -.28 & t(83)=2.7, p=.007 \text {. For Memory } \Delta 2 \text {, brand A was significantly different from brand } B, t(86)=3.4 \text {, } \\ \text { Control } & -.20 & -.05 & p=.00, \text { and from the control, } t(78)=2.5, p=.01\end{array}$

\section{Q9: Bellef that brand A can improve their life}

$\begin{array}{llll}\text { Brand A } & 1.08 & 1.06 & \text { For Memory } \Delta 1 \text {, brand A was significantly different from brand } B, t(86)=2.4, p=.01 ; \text { and from the control, } \\ \text { Brand B } & -.27 & -.54 & t(83)=2.2, p=.03 \text {. For Memory } \Delta 2 \text {, brand A was significantly higher the brand } B, t(85)=3.7, p=.0001, \\ \text { Control } & -.05 & -.18 & \text { and from the control, } t(78)=2.7, p=.01\end{array}$

Q10: Likellhood to buy brand A

Brand A 34

Brand $B \quad-.63 \quad-.79$

Control $\quad .02 \quad .15$
Movement was more positive in the brand $\mathrm{A}$ condition, and more negative in brand $\mathrm{B}$ condition for

Memory $\Delta 1$, significantly different at $t(87)=2.3, p=.02$, and also significantly different for Memory $\Delta 2$, $t(86)=2.5, p=.01$. 


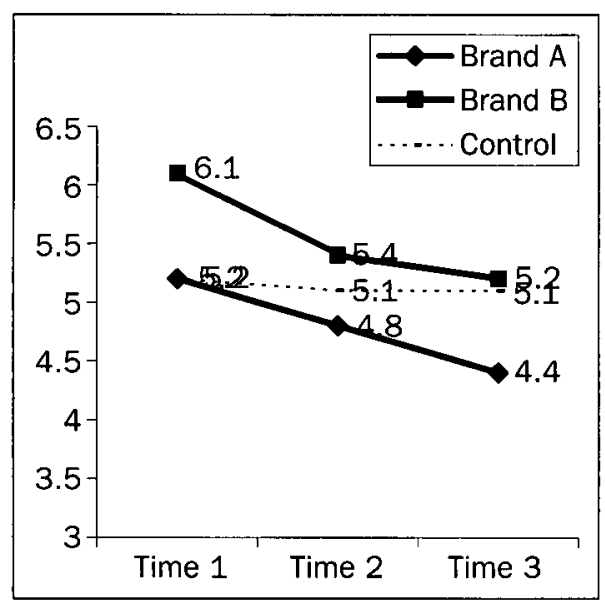

Figure 1 Graph of Memory Change: Question 1; Predicted Direction: Down for Advertising Groups

either beliefs about the brand or beliefs about brand A. Brand A, however, had a large impact on how consumers recalled earlier feeling about that brand, on effectiveness, "balance," and purchase intent. In addition, brand $\mathrm{A}$ appeared to hurt brand B's effectiveness and each participant's belief in that drug's ability to bring his/her life into balance.

\section{Indirect measures of advertising's impact}

As a distraction task between the advertisement viewing and memory measures, and as a first task for the control group, participants were told: "Below is a list of partially completed words. Complete them with whatever word comes to your mind first. We'll spend about five or so minutes on this page." The following partially completed words were presented:

$$
\begin{aligned}
& \mathrm{TR}_{---} \mathrm{F}_{--} \mathrm{MA}_{-} \mathrm{IO}_{-} \text {; } \\
& \text { AN_ICI_AT_N; IG_IT _; } \mathrm{CA}_{--} \text {; } \\
& \mathrm{P}_{-} \mathrm{OA} \mathrm{A}_{-} \mathrm{IV} \text { _; _UA _ } \mathrm{TY} \text {; } \\
& \text { _ } \mathrm{OMF}_{-} \mathrm{R}_{-} ; \mathrm{TR} \mathrm{TR}_{---} ; \mathrm{GUA}_{-} \mathrm{AN}_{\text {; }} \\
& { }_{-} \mathrm{NNEC}_{-} \mathrm{ON}_{\mathrm{O}} \mathrm{AP} \mathrm{AO}_{-} \mathrm{C}_{-} \text {. }
\end{aligned}
$$

The answers we were looking for were: transformation, anticipation, dignity, care, proactive, quality, comfort, trust, guardian, connection, and approach. In other research, these words were found to be related to important constructs concerning the product and brand the advertising was intending to address. If the advertisement had successfully "primed" those ideas, then there would be more completion of the words in the advertising conditions (particularly for brand A, which was designed to address such ideas; this measure is similar to Shapiro and Krishnan, 2001).

Brand A's advertisement was more effective than brand B's advertisement and the control condition in activating the target words. The overall results appear in Table 3. This greater activation may be due to the fact that brand A was offering new information in a very different manner than the brands that were currently advertising. These results present independent validation of the greater influence of brand A's commercial (which was observed also in the memory change measures). Both the memory change and implicit word completion task address the unconscious influences of the advertising.

\section{Other measures}

At the commercial viewing session, participants recorded their thoughts about the commercial and also rated it on a number of scales. The four key "attitude toward the advertisement" measures had participants rate the advertisement on four 10 -point semantic differential scales, anchored by the terms unfavorable-favorable, bad-good, unpleasant-pleasant, and negative-positive. These four scales have been used in past marketing research to assess consumers' attitudes toward an advertisement. We found the scales to load on one factor, with Cronbach alpha $=.93$; and they were averaged to form an index of "attitude toward the advertisement." This index was used for the analysis. The brand $\mathrm{B}$ advertisement was rated 8.0 (on the 10-point scale where higher values = more positive attitudes). The brand $\mathrm{A}$ advertisement was rated at 6.9 . These were found to be significantly different at $t_{(87)}=$ $3.06, p=.003$.

After the memory measures, participants were asked to rate how involved they became with the advertisement. These measures are often used to assess whether or not an advertisement has become internalized. For these measures, the participants indicated how much the advertisement "fit" or "doesn't fit" their situation on the following items: important to me, helpful, valuable, meaningful for me, worth remembering, and convincing. The scale was anchored by $1=$ "does not fit" and $10=$ "fits extremely well." We found these six items loaded on one factor, with Cronbach alpha of .96. We combined them to form an index of "advertising involvement." Participants rated the brand $B$ advertisement as being more involving than the brand $\mathrm{A}$ advertisement, 7.6 versus 7.2 , but this difference was not statistically significant.

\section{Competitive factors}

The attitude toward the advertisement measure indicated that brand B's reputation influenced how that advertisement was rated. We further assessed the competitive environment for brand A by asking participants to remember if they could recall having seen any other commercials related to the health concern issue addressed in the study. One of the difficulties brand $A$ has in entering an already established product category for which lots of advertising dollars have already been spent is that the new brand may inadvertently activate knowledge of the existing brands. For this analysis, we looked at recall differences between the new entrant brand $A$, the established brand 


\section{TABLE 3}

Implicit Word Completion Results

\begin{tabular}{|c|c|c|c|c|}
\hline & Brand A & Brand B & Control & Statistical Tests \\
\hline Transformation & $76 \%$ & $43 \%$ & $54 \%$ & $\begin{array}{c}\text { Brand A vs. brand B: } \chi_{(N=88)}^{2}=9.8, p=.001 ; \text { brand A vs. control, } \chi_{(N=84)}^{2}=3.6 \\
p=.05\end{array}$ \\
\hline Anticipation & $80 \%$ & $79 \%$ & $65 \%$ & Brand A vs. control: $\chi_{(N=84)}^{2}=2.1, p=.1$ \\
\hline Dignity & $17 \%$ & $6 \%$ & $25 \%$ & Brand B vs. control: $\chi_{(N=92)}^{2}=6.2, p=.01$ \\
\hline Care & $17 \%$ & $14 \%$ & $6 \%$ & \\
\hline Comfort & $75 \%$ & $60 \%$ & $61 \%$ & Brand A vs. brand $B: \chi_{(N=88)}^{2}=2.5, p=.1$ \\
\hline Proactive & $70 \%$ & $60 \%$ & $65 \%$ & \\
\hline Approach & $\mathbf{7 5} \%$ & $60 \%$ & $47 \%$ & $\begin{array}{l}\text { Brand A vs. brand } B: \chi_{(N=88)}^{2}=2.5, p=.1 ; \text { brand A vs. control: } \chi_{(N=84)}^{2}=7.5 \\
p=.006\end{array}$ \\
\hline Trust & $12 \%$ & $16 \%$ & $14 \%$ & \\
\hline Guardian & $68 \%$ & $43 \%$ & $54 \%$ & Brand A vs. brand B: $\chi_{(N=88)}^{2}=5.8, p=.01$ \\
\hline Connection & $87 \%$ & $79 \%$ & $72 \%$ & Brand A vs. control: $\chi_{(N=88)}^{2}=3.2, p=.07$ \\
\hline Quality & $56 \%$ & $37 \%$ & $45 \%$ & Brand A vs. brand $B: \chi_{(N=88)}^{2}=2.8, p=.09$ \\
\hline Overall number identified & 7.0 & 5.5 & 5.6 & $\begin{array}{l}\text { Brand A vs. control } t(86)=1.96, p=.05 ; \text { brand A vs. brand } B t(88)=2.45 \\
\qquad p=.01\end{array}$ \\
\hline
\end{tabular}

$B$, and control conditions. If there is overall more memory for another brand's advertising in a certain condition, it would be evidence that prior knowledge may be influencing consumers' perceptions of the test advertisement.

We found that in both the brand $A$ and brand $\mathrm{B}$ advertising conditions, recall for other drug advertisements related to this health issue was higher (73 and 67 percent) than in the control condition (53 percent), but that only the brand A condition was significantly different from the control condition at $\chi_{(N=85)}^{2}=3.17, p=$ .01 . The two advertising conditions were not statistically different from one another. This demonstrates that seeing the new brand A commercial activates memories of commercials that would not have been activated otherwise.
We also looked specifically at what advertisements were remembered and found that 54 percent in the brand A group recalled advertisements for the existing leader brand B, 59 percent in the brand B group recalled other advertisements for brand B, and 30 percent in the control group reported seeing an advertisement for brand $B$ in the past. Both advertising conditions were significantly higher than the control, $\chi_{(N=92)}^{2}=6.5, p=.01$ for the comparison between brand $B$ and the control, and $\chi_{(N=85)}^{2}=4.4, p=.04$ for the comparison between brand $A$ and the control condition. The two advertising conditions were not significantly different from one another. This demonstrates that the existing leader brand $\mathrm{B}$ benefits when they both advertise because of the information that the consumer is currently receiving as well as through the activation/reinforcement of prior information from memory. The new entrant, brand $A$, will activate prior knowledge of other brands when they advertise, until they have developed a strong enough new-brand schema. Until that point, however, they risk brand or advertising confusion (where consumers may associate their advertising with a better-known brand).

Had we not looked at the memory change scores but rather at the absolute ratings, such as the recall and the attitude measures, then we would have concluded that brand B's advertising was more influential. However, because that brand had saturated the market, seeing one more advertisement for brand B had little influence on the internalization process. Consumers already "knew" that brand, and 
the test advertisement was not adding anything new to that schema. The greater influence on memory observed for brand A may be partly due to the fact that consumers knew little or nothing about the brand prior to the advertisement viewing session. As that brand becomes better known, it too may reach a saturation point (as found with the brand $\mathrm{B}$ condition), where the attitude/memory becomes more stable and less resistant to alteration from new information.

\section{Relationship between traditional advertising measures and memory reconstruction}

As found in psychological and marketing research, there was little if no relationship between our explicit measures of advertising effectiveness and our memory change measure: $r=-.07$ between attitude toward the advertisement and the number of memory indicators changed, and $r=.07$ between advertising involvement and number of memory indicators changed. The two explicit advertisementrating measures were highly correlated: .63 with one another, however. The indirect measures of influence-memory change and implicit word completionshowed only a small positive correlation $(r=.12)$.

\section{Discussion}

Advertising researchers have debated whether memory or persuasion measures are the best way to determine advertising effectiveness. The pendulum is swinging toward persuasion. An advertisement that is memorable may be unfocused (Garfield, 1997) or worse, memorable and adversely impact sales (Jones, 1995). Blair and Rosenberg (1994, p. 36) state: "Recall is not a consistently accurate measure; about half the time, recall results are predictive of in-market results, leading to a false reliance on related recall as an advertising

The research reported here suggests that memory and persuasion ought to be considered together, rather than as distinct units. The reconstructive nature of recall is essential for understanding the persuasive impact adver-

\section{tising has on consumers.}

criteria measure." The research reported here suggests that memory and persuasion ought to be considered together, rather than as distinct units. The reconstructive nature of recall is essential for understanding the persuasive impact advertising has on consumers.

Considerable progress has occurred recently in understanding how advertising influences consumer cognitions. Such progress, though, has left some researchers believing that advertisement testing may be more difficult than originally thought: "We may never be able to parse out the effects of advertising from all the other marketing factors and marketing communication forces that affect consumer interactions with and predispositions for and against individual brands. There may be no direct line of consumer questioning that can ever tap into exactly what happens in a person's mind, either generally or specifically, with respect to the perception of brands" (Weilbacher, 2001, p. 20).

We believe that the memory integration paradigm isolates the impact of advertising exposure almost immediately after exposure and parses out other influences. What it reveals, which is a consumer's own memory change due to exposure, is a very intimate measure of advertising impact because it is the consumer's memory of their own thoughts and feelings about an issue that is being recalled rather than their memory of what was presented by someone or something else. The former indicates persuasion whereas the latter may not. Put differently, this approach focuses on the consumer rather than the advertisement. Evaluating the impact of advertising on consumers' memories for their beliefs and attitudes is thus a truer indication of advertising's impact or lack thereof than the self-report measures typically employed for copy testing. This measure is "undistorted" by demand characteristics associated with asking people directly about how much they believed an advertisement. The internalized recalled belief will have more "staying power" than a belief/attitude measured in response to the advertising taken immediately (note here our strong correlation, .64 between beliefs recalled immediately after an advertising exposure and beliefs reported two to three days following exposure).

When evaluating an advertisement for a new brand to be launched in an already developed product category, knowledge of other brands is likely to taint how that new brand is perceived (as indicated in our study). In relation to other advertisements, that new brand's advertisement may rate lower due to less familiarity rather than an objective rating of the advertisement's message (e.g., the "halo 
effect"). Additionally, as consumers come to the advertisement-testing session with already established idiosyncratic attitudes, what is important is how the advertisement changes an individual's personal beliefs rather than looking at a group mean or average that can be swayed by a few extreme scores. The memory change measure takes into account past knowledge and reveals how much (or how little) impact the test advertisement has on consumer beliefs.

In other contexts, advertising has been shown to distort consumers' memories of past experiences (Braun, 1999) and has even resulted in the creation of false childhood memories of visiting Disneyland and meeting Bugs Bunny (Braun, Ellis, and Loftus, 2001). Taken together with the present findings, this suggests that advertising can have a tremendous impact on how consumers reconstruct their past knowledge. Because advertising is most likely to be noticed after a consumer has bought the advertised product (Lodish et al., 1995), advertising as a cause of memory reconstruction is probably a common occurrence. This is consonant with studies of dissonance reduction that suggest that people may use postdecision information to reinforce the merits of their decisions, thereby creating after-the-fact a greater sense of confidence in their initial decisions than may have actually been experienced. Therefore, paradigms such as the memory integration one offered here may be very beneficial in the study of advertising persuasion in the long run.

Because the goal of most advertising is to produce an enduring emotional impact, the usage of memory measures is appropriate. However, advertising researchers need to broaden their view of what constitutes memory. According to a recent advertising text, O'Guinn, Allen, and Semenik (1998) state that by far the most common method of advertising research continues to be the recall test. But memory is much more intimate and complex than what is captured through recall and recognition tests. As one of the authors has noted elsewhere (Zaltman, 2003, p. 165): "All of us assume that our memories inherently belong to us, accurately reflect reality, remain under our conscious control, and influence us only when we 'call them up' or 'bring them to mind.' Yet recent research in psychology, biology, sociology and neuroscience reveals that our assumptions about memory are tenuous at best. Memories are malleable: not only do they fade or disappear over time, they change every time they come to mind, with every new human experience." JAB

Kathryn Braun-LaTour is an assistant professor of hospitality marketing in the William F. Harrah College of Hotel Administration, University of Nevada, Las Vegas. She is also a memory researcher who has collaborated with Gerald Zaltman, of Olson Zaltman Associates, in developing the memory integration paradigm. She has published numerous articles demonstrating the power of advertising to change memory of prior consumer experiences.

Gerald Zaltman is a principal in the consulting company Olson Zaltman Associates and is also an emeritus professor at the Harvard Business School. He recently wrote How Customers Think: Essential Insights into the Mind of the Market, which reviews some of the cognitive forces upon which this research is based.

\section{REFERENCES}

Bartlett, F. C. Remembering. Cambridge, U.K.: Cambridge University Press, 1932.

Belli, R. F., D. S. Lindsay, M. S. Gales, and T. T. MCCARTHY. "Memory Impairment and Source Misattribution in Postevent Misinformation Ex- periments with Short Retention Intervals." Memory $\mathcal{E}$ Cognition 22, 1 (1994): 40-54.

Bettman, J. R. "Memory Factors in Consumer Choice: A Review." Journal of Marketing 43, 2 (1979): 37-53.

BlaIR, M. H., and M. J. RabUCK. "Advertising Wearin and Wearout: Ten Years Later-More Empirical Evidence and Successful Practice." Journal of Advertising Research 38, 5 (1998): 7-18.

_ and K. E. RosenberG. "Convergent Findings Increase Our Understanding of How Advertising Works." Journal of Advertising Research 34, 3 (1994): 35-45.

Braun, K. A. "Post-Experience Advertising Effects on Consumer Memory." Journal of Consumer Research 25, 1 (1999): 319-34.

, R. Ellis, and E. F. LofTus. "Make My Memory: How Advertising Can Change Our Memories of the Past." Psychology \& Marketing 19,1 (2001): $1-23$

- and G. Zaltman. "Backward Framing: A Theory of Memory Reconstruction." MSI's Working Paper Series, \# 98-109, Marketing Science Institute, Cambridge, MA, 1998.

Burke, R. R., and T. K. SRull. "Competitive Interference and Consumer Memory for Advertising." Journal of Consimmer Research 15, 1 (1988): $55-69$.

ClarK, E. The Want Makers: Inside the World of Advertising. New York: Penguin Books, 1985.

Crick, F., and C. Косн. "Consciousness and Neuroscience." Cerebral Cortex 8, 2 (1998): 97-107.

Edelman, G. Wider than the Sky. New Haven, CT: Yale University Press, 2004 
Ehrenberg, A., N. Barnard, R. Kennedy, and H. Bloom. "Brand Advertising as Creative Publicity." Journal of Advertising Research 42, 4 (2002): $7-19$.

Fauconnier, G., and M. Turner. The Way We Think: Conceptual Blending and the Mind's Hidden Complexities. New York: Basic Books, 2002.

Feldman, J. M., and J. G. LynCH, JR. "SelfGenerated Validity and Other Effects of Measurement on Belief, Attitude, Intention and Behavior." Journal of Applied Psychology 73, 3 (1988): 421-35.

Franzen, G., and M. Bouwman. The Mental World of Brands. WARC, UK: World Advertising Research Centre, 2001.

Gardner, H. Changing Minds: The Art and Science of Changing Our Own and Other People's Minds. Boston, MA: Harvard Business School Press, 2004.

Garfield, B. "Super Bust." Advertising Age, January 27, 1997.

Goethals, G. R., and R. F. Reckman. "The Perception of Consistency in Attitudes." Journal of Experimental Social Psychology, 9, 6 (1973): 491-501.

Haley, R. E., and A. L. Baldinger. "The ARF Copy Research Validity Project." Journal of Advertising Research 40, 6 (2000): 114-36.

Hal.l, B. F. "A New Model for Measuring Advertising Effectiveness." Journal of Advertising Research 42, 2 (2002): 23-32.

Hawkins, S. A., and R. Hastie. "Hindsight: Biased Judgments of Past Events after the Outcomes Are Known." Psychological Bulletin 107, 3 (1990): 311-27.
Hunter, I. M. L. Memory. London: Penguin, 1964.

Jones, J. P. When Ads Work: New Proof that Advertising Triggers Sales. New York: Lexington Books, 1995.

Kovecses, Z. Metaphor and Emotion: Language, Culture, and Body in Human Feeling. Cambridge, UK: Cambridge University Press, 2000.

LeDoux, J. E. The Emotional Brain: The Mysterious Underpinnings of Emotional Life. New York: Simon and Schuster, 1996.

LIBEт, B. Mind Time: The Temporal Factor in Consciousness. Boston, MA: Harvard University Press, 2004.

Lodish, L. M., M. Abrahamson, S. KalmenSON, J. LiVElsBerger, B. LUBETKIN, B. Richardson, and M. E. Stevens. "How T.V. Advertising Works: A Meta-Analysis of 389 Real World Split Cable T.V. Advertising Experiments." Journal of Marketing Research 32, 2 (1995): 124-39.

LofTus, E. F., and K. Keтchum. Myth of Repressed Memory: False Memories and Allegations of Sexual Abuse for the Defense. New York: St. Martin's Griffin, 1996.

—, and J. E. Pickrell. "The Formulation of False Memories." Psychiatric Annals 25, 12 (1995): 720-25.

Maloney, J. C. "Curiosity Versus Disbelief in Advertising." Joumal of Advertising Research 40, 6 (2000): 7-13.

McQuARrie, E. F. "Have Laboratory Experiments Become Detached from Advertiser Goals?" Journal of Advertising Research 38, 6 (1998): 15-25.

Neisser, U. "John Dean's Memory: A Case Study." Cognition 9, 1 (1981): 1-22.
Nisbett, R. E., and T. D. Wilson. "Telling More Than We Can Know: Verbal Reports on Mental Processes." Psychological Review 84, 3 (1977): 231-59.

O'Guinn, T., C. T. Allen, and R. J. Semenik. Advertising. Cincinnati, $\mathrm{OH}$ : Southwestern Publishing, 1998.

Pezdek, K. "Event Memory and Autobiographical Memory for the Events of September 11, 2001." Applied Cognitive Psychology 17, 9 (2003): 1033-45.

PINkER, S. The Blank Slate: The Modern Denial of Human Nature. New York: Penguin Books, 2002.

Reber, A. S. Dictionary of Psychology. London: Penguin, 1985.

Ross, M. "Relation of Implicit Theories to the Construction of Personal Histories." Psychological Review 96, 2 (1989): 341-57.

SCHACTER, D. Searching for Memory. New York: Basic Books, 1996.

The Seven Sins of Memory: How the Mind Forgets and Remembers. Boston: Houghton Mifflin, 2001.

Schmolck, H., E. A. Buffalo, and L. R. Squire. "Memory Distortions Develop over Time: Recollections of the O.J. Simpson Trial Verdict after 15 and 32 Months." Psychological Science 11, 1 (2000): 39-45.

Shapiro, S., and H. S. Krishnan. "MemoryBased Measures for Assessing Advertising Effects: A Comparison of Explicit and Implicit Memory Effects." Journal of Advertising 30, 3 (2001): 1-14.

Smith, R. E., and W. R. Swinyard. "AttitudeBehavior Consistency: The Impact of Product 
Trial Versus Advertising." Journal of Marketing Research 20, 2 (1983): 257-67.

Squire, L. R., and B. J. Knowlton. "The Medial Temporal Lobe, the Hippocampus, and the Memory Systems of the Brain." In The Cognitive Neurosciences, 2nd ed., M. Gazzaniga, ed. Cambridge, MA: MIT Press, 1999.
Thomson, D. M., and E. Tulving. "Associative Encoding and Retrieval: Weak and Strong Cues." Journal of Experimental Psychology 86, 2 (1970): 255-62.

WeGner, D. M. Illusion of Conscious Will. Cambridge, MA: MIT Press, 2002.
Weilbacher, W. M. "Point of View: Does Advertising Cause a "Hierarchy of Effects"?" Journal of Advertising Research 41, 6 (2001): 19-27.

Zaltman, G. How Customers Think: Essential Insights into the Mind of the Market. Boston, MA: Harvard Business School Press, 2003. 
Copyright of Journal of Advertising Research is the property of World Advertising Research Center Limited and its content may not be copied or emailed to multiple sites or posted to a listserv without the copyright holder's express written permission. However, users may print, download, or email articles for individual use. 